\title{
An Interaction-based Approach for Structuring Coordination Activities
}

\author{
Lars Taxén
}

\section{Linköping University Post Print}

\section{Tweet}

N.B.: When citing this work, cite the original article.

Original Publication:

Lars Taxén , An Interaction-based Approach for Structuring Coordination Activities, 2002, Proceedings of the First IEEE International Conference on Cognitive Informatics (ICCI'02), 270-279.

http://dx.doi.org/10.1109/COGINF.2002.1039307

Postprint available at: Linköping University Electronic Press

http://urn.kb.se/resolve?urn=urn:nbn:se:liu:diva-111358 


\title{
An Interaction-based Approach for Structuring Coordination Activities
}

\author{
Lars Taxén \\ Ericsson AB / Dept of Computer Science, Linköping University \\ Box1505 S-125 25 ALVSJO, Sweden \\ lars.taxen@era.ericsson.se
}

\begin{abstract}
In this contribution we present a theoretical approach which has been utilized to inform the coordination of the development of complex systems. Coordination is regarded as a form of human activity in which individual and social aspects as well as technical ones need to be considered. We analyze human activity from an interaction point of view in which various types of signs mediate the relation between individual cognition and phenomena in the environment. The sign-mediated interaction is apprehended as having a connectional, conceptual and linguistic facet. From a cognitive and semiotic analysis of these facets, we conjecture that the following constituents are fundamental for human activity: intersubjectivity, experiential learning, contextuality, spatiality, temporality, stabilizing core and tool usage. These constituents are employed in structuring human activity from a coordination point of view as activity domains. A framework for articulating activity domains is described. This framework, which includes information system support, is currently used to coordinate the software integration of the 3:rd generation mobile systems at the Ericsson company. We report on some result from this usage. The results indicate that the theoretical approach is relevant for practical purposes.
\end{abstract}

\section{Introduction}

When developing large software systems the coordination of the development activities is a critical task. For example, the software for a single node in the 3:rd generation mobile telecommunication network may contain millions of lines of code which are developed in several hundred increments by designers all over the world. These increments are in general dependent on each other and must be integrated and tested in a certain order. Moreover, the customer requirements of the system often change during the development which makes the coordination even more complicated.

An example of the complexity of these kinds of coordination tasks is given in Figure 1, which illustrates the dependencies between the increments in the so called mobile switching center node in the network. Every white box indicates a certain increment and each line a dependency. The thick arrows mark the content and date for a particular integration and verification of a number of increments. The 'bubbles' represent basic services in the node like registration of the location of the mobile, calling to the mobile, answering a mobile call etc. In most cases the functionality is provided by software, but some increments contain hardware technology as well. By and large, the figure illustrates one aspect of the coordination of a large software development project: managing the dependencies between activities.

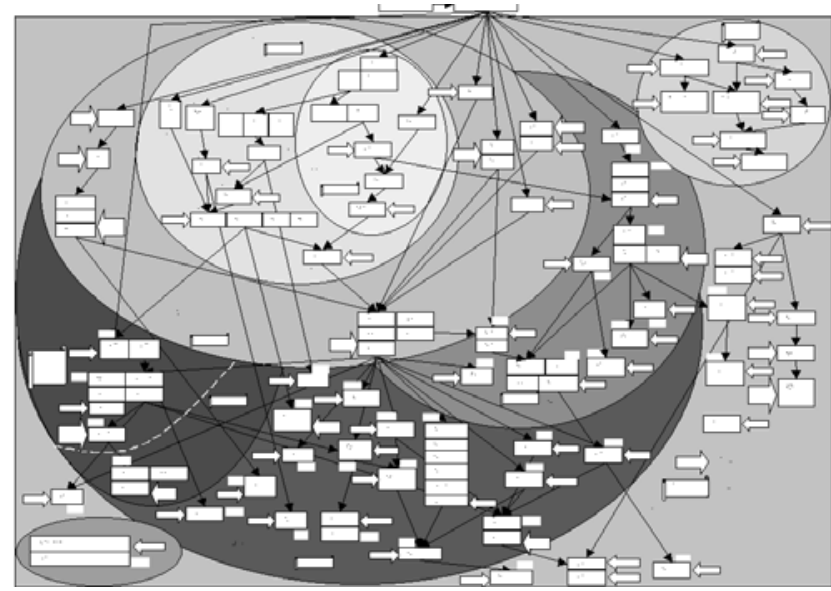

Figure 1. Dependencies between increments

The coordination of these kinds of development tasks cannot only be regarded as a technical matter. Individual cognition and social aspects have to be considered as well, for example, agreeing upon what the coordination is all about. Issues like understanding, meaning and interpretation need to be included. A pure formalistic approach where these issues are neglected will be inadequate.

Apprehended in this way, coordination may be regarded as an aspect of a socially organized human activity with the purpose of developing complex systems. In order to inform the structuring of this activity from a coordination point of view, a theoretical perspective on human activity is needed which focus on the dynamic interaction between individuals, society and technology.

The nature of the relationship between the individual and the society has been the subject of an ongoing philosophical discourse for many years. In general the constituents of human activity have been seen either as individual action or social structures. Some philosophers have focused on the interaction between the individual and soci- 
ety, for example Hegel [1], Berger \& Luckmann [2], Kosík [3] and, more recently, Giddens [4] and Seo \& Creed [5].

Some of the theories proposed have been appropriated to inform the construction of information systems (IS), for example, the Structuration Theory of Giddens [6]. However, there are few practical and useful results reported [7]. Other theoretical approaches are the Actor Network Theory [8],[9], Activity Theory [10] and Organizational Semiotics [11]. Again, the practical results of appropriating these theories for constructive purposes appear to be limited [12].

In this paper we propose to structure socially organized human activity from an interaction point of view. Interaction is regarded as the genesis of human knowledge and the formative power of both individual cognition and social phenomena such as artefacts, institutions, norms etc. We ground the concept of interaction in the dialectical relation as understood in the marxist praxis tradition [3].

The interaction is considered to be mediated by various types of signs. The essence of signs is that they have a material and cognitive side and thus are suitable to relate individual cognition to phenomena in the environment. In order to arrive at a characterization of human activity we apprehend the sign-mediated interaction as having a connectional, a conceptual and a linguistic facet. The connectional facet is associated with the neural network in the brain, the conceptual facet with the conceptual forming capabilities of man and the linguistic facet with human language capabilities.

From a cognitive and semiotic analysis of interaction thus apprehended we conjecture that the following constituents are fundamental for human activity: intersubjectivity, experiential learning, contextuality, spatiality, temporality, stabilizing core and tool usage.

The fundamental constituents are employed in structuring human activity from a coordination point of view as activity domains. In activity domains, the coordination of productive or value-adding activities are in focus. Moreover, the constituents have been informing the design of a framework in order to articulate activity domains. This framework includes a number of models which are implemented in an information system in order to support the coordination activity.

We discuss some results of applying the framework in development projects at the Ericsson telecommunication systems company. The results show that the framework improves various aspects of the coordination, which in turn is an indication of the validity and practical relevance of the theoretical approach.

\section{The character of coordination}

According to Malone \& Crowstone "Coordination is managing dependencies between activities" ([13], p.90). Thus coordination is an activity in itself which has as its object other activities.

In the development of complex systems, the coordination activity is only one type of activity needed. In the literature, it is customary to separate between productive and managerial activities. Productive activities are activities that trans- form an object from one condition to another, while managerial activities are evoked to manage the transformational activities. Thus, coordination activities are nontransformational activities in the development context.

Some examples from the Ericsson practice of objects involved in the coordination are:

- The system and its describing documents.

- Requirements on the system as stated by the customer.

- Trouble reports describing various types of errors.

- Engineering change orders calling for controlled changes of the system.

- Baselines which describe a certain achieved configuration of the system which cannot be changed without specific control procedures.

- Incremental deliveries during the project where parts of the complete specification are fulfilled.

- Test cases which are used to test that the system fulfils its specification.

- Milestones controlling the progress of the project.

In the context of coordination we will refer to these objects as managed items.

In order to articulate the coordination we need to know what activities should be coordinated. We also need to know which managed items are impacted by that coordination and how these items are related to each other. The dependencies between managed items impose constraints of the coordination. For example, a test case testing a particular software unit cannot be executed before the software has been compiled and integrated with other units.

Moreover, the actors carrying out coordination need to have some shared understanding about the coordination contexts. "How, for instance, can actors establish common languages that allow them to communicate in the first place?" ([13], p.99). Since these actors at Ericsson may be geographically dispersed, have different roles, come from different traditions, speak different languages etc. a major problem is how to achieve the necessary shared understanding. Furthermore, the meaning and content of the coordination need to evolve according to new insights, new demands form the market, new tools and methods supporting coordination etc.

This means that we may apprehend coordination as an aspect of a dynamic form of human activity. As with any organized human activity, there is an individual side and a social side of the activity. Each individual actor is unique in terms of capabilities, motives, attitudes, desires, anxieties etc. At the same time there is a trans-individual side of the activity which concerns shared understanding, norms, rules, support systems etc. This dual perspective will be further elaborated in the following sections.

\section{A sign-mediated model of interaction}

In order to arrive at a theoretical approach informing the structuring of human activity, we use the concept of praxis as a point of departure [3]. The ontology of praxis 
can be summarized as follows: There is an objective world which exists independent of human beings. However, the knowledge human beings have about this reality is intrinsically related to the cognitive capabilities of man. This does not mean that our knowledge is only subjective and private. On the contrary, every individual understanding of the world is grounded in the social, intersubjective conditions of mankind, above all a language. The genesis of knowledge is the interaction between humans and their environment. Thus the knowledge and capabilities of humans are located in the individual, but they emerge in interaction with the particular situations in time and space in which the individual engages during her life-time.

In the praxis tradition, the interaction takes the form of the dialectical relation between the individual and her environment. In this paper we regard the dialectical relation as the fundamental character of interaction. A dialectical relation between two pairs of opposites is internal, which means that opposites are different but mutually depending on and impacting each other within a totality. An example of such a relation from Hegel [1] is the relationship between master and slave. These categories do not have any meaning taken one by one. There cannot be any master if there is no slave and the other way around. The master is dependent on the slave and the slave on the master.

Another aspect of a dialectical relation concerns the parts - whole relationship. It is commonly accepted that the whole is something more than a mere compilation of parts. The whole acquires properties from the parts. However, also the parts themselves acquire new properties by being part of a whole. For example, no matter how much a person flaps with her arms, she cannot fly. Neither can a group of people fly by flapping their arms together. However, if they get together in socially organized work, i.e. praxis, they can indeed develop airplanes, fuel supplies, airports etc. and thereby in fact fly. By being part of an airplane engines, pilot and passengers acquire a qaulitatively new property: they can be transported over long distances through the air.

The interaction between the individual and her environment is mediated by various types of signs. The essence of signs is that they have a material and cognitive side and thus are suitable to relate individual cognition to phenomena in the environment. de Saussure defined a sign as the unity of a signifier and a signified [14]. According to Vološinov "any item of nature, technology or consumption can become a sign, acquiring in the process a meaning that goes beyond its given particularity" [15]. This means that anything that the individual cognitive system can perceive may be regarded as a sign. The signifier side of the sign relation relates something material in the environment to 'sensory images' in the brain. This might be brought to the organism in the form of sound waves, photons, chemical scents etc. A particular perceived pattern in the environment has a corresponding pattern in the neural network of an individual which has interacted with the environment long enough to form that pattern. This pattern apprehended as concepts signifies some phenomena in the environment (see Figure 2).

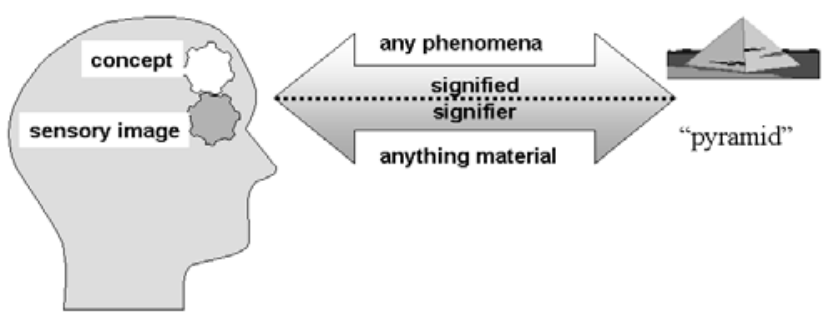

Figure 2. Signs as mediators

In order to arrive at a characterization of human activity we structure the sign-mediated interaction in a connectional, conceptual and linguistic facet. This structuring is an elaboration of a model for representing the cognitive system of the brain suggested by Gärdenfors [16]. In each facet we define what aspect or type of signs is in focus.

In the first facet, the connectional, we focus on the neural network of the brain. This facet consists of a large number of simple but highly connected units called neurons. These receive excitatory or inhibitory inputs and transmit activity to other units according to some function of the inputs. The processing is done in parallel and the strength of the connections between the units changes according to made experiences from the interaction with the environment. The result of the organism's interaction with the environment is the formation of patterns of connected neurons. The signifying aspect in focus in this facet is signals or perceived stimuli closely related to events in the immediate spatial and temporal environment of the organism.

The next facet is the conceptual one. In this facet we focus on the conceptual forming capabilities of humans. The underlying neural patterns in the brain are apprehended as concepts which are spatially related to each other [16]. In this way, the patterns of the neural network are collapsed into regular structures which can be conceived in the conceptual facet through a reduction of numerous neural dimensions to a few conceptual dimensions. Concepts are made up from basic quality dimensions [16]. Examples of such quality dimensions are temperature, weight and spatial dimensions like height, width and depth. The quality dimensions are associated with geometrical, topological or ordering structures (time being one of them) and they are the basis for building what Gärdenfors calls conceptual spaces [16]. Correspondingly, the signifying aspect in focus in this facet is concepts and their relations. This means that phenomena are signified without necessarily associating them with a linguistic element such as a name.

The last facet is the linguistic one. In this facet we focus on the linguistic capabilities of man. Language is apprehended as a sign system where the association between the signifier and the signified is arbitrary, i.e. the sign is a symbol. For example, signifiers like 'dog' (english), 'chien' (french) or 'Hund' (german) all signify the same concept. For a comprehensive discussion on language and 
signs, see de Saussure [14].

The essence of the sign-mediated interaction structure (see Figure 3) is that we have shifted the perspective from regarding individual and social aspects of human activity in isolation into regarding these aspects as different types of signification between the individual and her environment. We have also defined what aspect of signs we associate with each facet. In the connectional facet signs are apprehended as signals, in the conceptual facets as related concepts and in the linguistic facet as symbols. These aspects correspond roughly to the classification of signs as indices, icons and symbols proposed by Pierce([14], p 9).

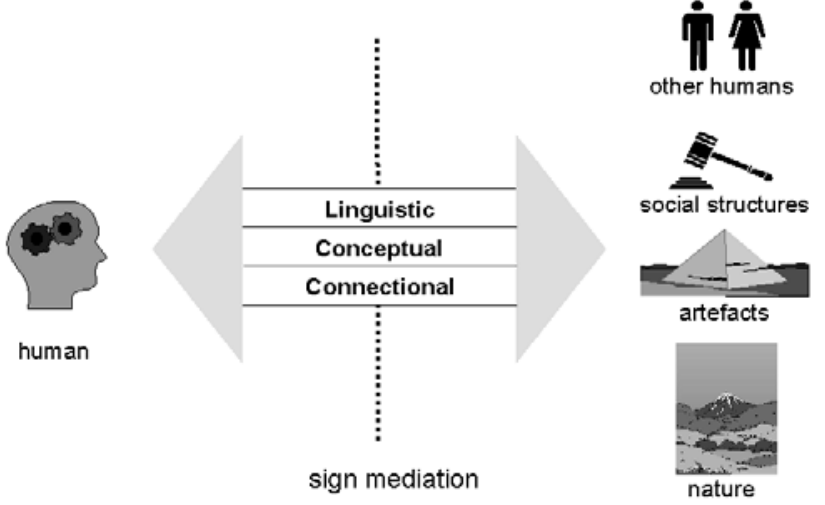

Figure 3. Sign-mediated interaction

The sign-mediated interaction should not be apprehended as a representation of 'real' interactions in nature. There is nothing in the external world which materializes the interaction. The cognitive apparatus of organisms still reside in the nervous system in the brain. Likewise, it does not change the fact that there exist a natural and social world. The point of focusing on the interaction in the form of a dialectical relation rather than on either the individual or the social, is that we consider this to be a more viable way to address problems regarding semiosis and genesis, i.e. formative and creative aspects of the socially organized human world. Thus, our scientific position with respect to this model is basically instrumental (see Chalmers [17]).

\section{Human activity structured as Activity Domains}

In order to structure socially organized human activity from a coordination point of view, we propose the notion of activity domains. This means that in activity domains, the focus in on the coordination of productive activities. The internal structure of the productive activities is concealed in a particular activity domain.

Activity domains are similar in purpose as Activity Systems in Activity Theory [10] but differently structured. In an activity domain the actors have a motive for coming together, which is the reason why the activity domain exists. The actors are working together on an object to produce a certain outcome. The object is the main driver for organizing the activity domain.
Each productive activity can internally be structured as an activity domain. This means that the notion of activity domain is a recursive construct. Thus, activity domains interact with each other to produce a concerted outcome.

The structure of an activity domain as proposed in this paper is inspired from an analysis of the different facets of the sign-mediated interaction as described in section 3 . The analysis is mainly grounded praxis theory ([3], [18]), cognitive and linguistic sciences ([16], [15]) and learning theories [19] and identifies a number of salient features which are found in all or several facets (see [12] for details):

- Intersubjectivity: Intersubjectivity arises in the interaction between humans and is a prerequisite for the emergence of various sign systems, above all language.

- Signification: The interactions in the activity domain are mediated by signs of various types which signify which phenomena are perceived and interpreted as relevant in the activity domain.

- Experiential learning: The capabilities and knowledge of actors in the activity domain are achieved in an ongoing alteration between reflection and action. Change is regarded as endemic rather than exceptional. Examples of this constituent are the four-stage cycle of learning discussed by Kolb [19] or the iterative Rational Unified Process (RUP) in software development.

- Stabilizing core: An activity domain always has a stabilizing core which provides a proper balance between order and disorder in the domain. The core is a prerequisite for meaningful actions. Examples of this constituent are internalized social norms or a common way of identifying products within a product development organization.

- Contextuality: Intersubjectivity and experiential learning are always related to a certain context or situation. A context for human action has a focus and is limited in extension. The focus may change. When the action crosses context borders a translation between the context boundaries may become necessary. Examples of this constituent are software and hardware development activities and the need to translate software constructs into hardware constructs when both types of development interact.

- Spatiality: There is a spatial / static structure in an activity domain. This structure signifies the phenomena actors perceive in the activity domain and how these relate to each other. This means that the spatial / static view of the activity domain defines the context of the same domain. An example of this constituent is an object-relational model i system design.

- Temporality: There is a temporal / dynamic structure in the activity domain. This structure signifies how actions in the activity domain are coordinated. An example of this constituent is a process model in system design. The spatial and temporal structures interact 
with and influence each other.

- Tool usage: the usage of tools is an intrinsic part of human activity. An example of this constituent is an information system.

Since these features are common to several facets, we conjecture that they are fundamental and can be found in every socially organized human activity. We will call these features fundamental constituents. We do not claim that the constituents proposed here are exclusive or that other constituents may not be equally fundamental. However, we claim that they are vital for constructive and explanatory purposes when structuring human activity from a coordination point of view. Again, our scientific position w.r.t. to these fundamental constituents is instrumental ([17]).

In summary, the structure of activity domains is given in Figure 4:

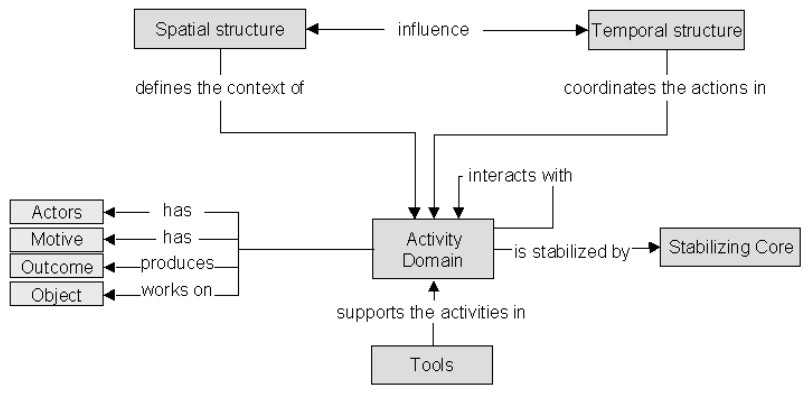

Figure 4. The structure of activity domains

\section{A framework for coordination}

Activity domains are socially organized human activity structured for coordination purposes. The structuring is informed by the fundamental constituents and has the general form illustrated in Figure 4. In a particular coordination situation the activity domain must be given a concrete content and form which comply with the coordination situation. We may consider this process as an articulation of a specific activity domain. In order to support this articulation a framework has been developed and deployed in the Ericsson development practice. The design of the framework has been informed by the fundamental constituents. The application focus of the framework is project management of large development projects. It consists of three models, an $I S$ and a strategy for articulating the coordination context.

The static structure of the activity domain $t$ is modeled by a spatial domain model which capture what managed items are subject of coordination and how they relate statically to each other. This model also expresses the boundaries of the activity domain. Items not visible in the model are not relevant in the activity domain. The particular notation of the model may for example be the Unified Modeling Language (UML) or any other object-relation type of model.

The dynamic structure of the same context is modeled by a temporal domain model which captures the dependencies between productive activities impacting the managed items.
Thus this model corresponds closely to the definition of coordination given by Malone \& Crowstone [13]. In the framework entity based process models are used [20].

The translation across activity domain boundaries is modeled by a domain translation model, which is based on the Specification-based Data Model (SBDM) by Gandhi \& Robertson [24]. The translation includes both a mapping between the constructs in the domains and an interpretation of the meaning of these constructs.

Altogether, these three models articulate the contextual, spatial and temporal constituents of the activity domain. The tool constituent is articulated by implementing these models in an IS which is called domain articulation tool in the framework. In this tool instances of the managed items are manipulated to support the coordination of a particular development task.

To achieve a shared understanding or intersubjectivity about the relevance structure of the activity domain, a domain articulation strategy is included in the framework. In this strategy, the articulation of the models and their implementation in the IS take place in an ongoing alternation between reflection phases and action phases. In the reflection phase actors reflect upon the models and their implementation in the IS and in the action phase they try them out in ongoing development tasks. This means that the models and the IS act as instruments for the signification process between the actors. In this way, the experiential learning, the intersubjectivity and the signification constituents are invoked.

In order for this strategy to work, the IS must be exceptionally easy to modify. This also means that there is no detailed specification of the IS. Rather the specification is on a content level, for example, 'requirement management should be implemented'. Thus, an evolutionary development strategy for the IS is applied [21].

The models, the shared understanding and the implementation of the models in the IS emerge in a dialectical way, i.e. there is an ongoing mutual interaction between individual human aspects and social aspects in the form of the models and the IS. During this process a stabilizing core may evolve if the actors can agree on a shared understanding about this core. However, this is by no means secured by the articulation strategy. The result may equally well be severe conflicts and disagreement about the extension and contents of the stabilizing core.

\section{Implementing the framework}

The articulation of the activity domain starts with a reflection phase where preliminary versions of the models are discussed and agreed upon among a group of actors. Usually the heaviest focus is on the spatial domain model. In Figure 5. an example of this model for managing requirements is shown. Elements which may be discussed in this model are

- the types of requirements,

- the states or life cycle of requirements, 


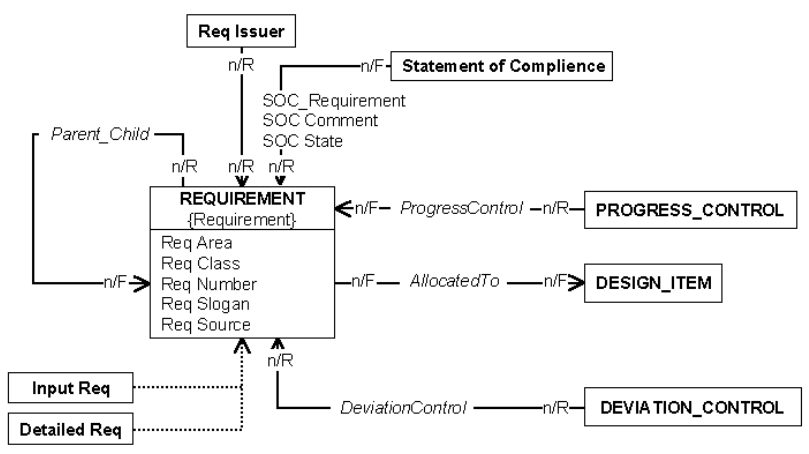

$$
\begin{array}{ll}
\text { Cardinality: } n=\text { many, } 1=\text { one } & \text { Revision stepping rules: } \\
\{x \times x\}=\text { state set name } & R=\text { replicate } \\
& F=\text { float } \\
N=\text { none }
\end{array}
$$

Figure 5. The spatial domain model - requirement focus

- attributes on requirements,

- relations to surrounding items such as requirement issuer,

- attributes on relations,

- cardinalities on relations,

- revision stepping rules which state how relations are treated when new revisions are instantiated of a requirement,

- icons representing requirements,

- actor roles in relation to requirements, for example 'requirement coordinator' or 'configuration manager',

- access rights for roles, i.e. who is allowed to do what with requirements, for example create or delete a requirement.

This model is implemented in a one-to-one manner directly in the IS. Each box becomes a type, each line a relation, texts on boxes becomes attributes etc. This concludes the reflection phase in the articulation strategy.

In the action phase of the articulation strategy the models and their implementation in the IS are tried out in practice. Instances of the types in the spatial model are created and related to each other, attributes are given values, state chains are instantiated according to the temporal model, actors are assigned roles, etc. Views of the data such as shown in Figure 6 are created, reports extracted and the experiences discussed among the actors. The outcome of this discourse provides the input for the next reflection phase where the models and the IS implementation are modified for the subsequent action phase.

In this way, the evolution of the models and their implementation in the IS continues all through the project and beyond to new projects. In this process, an intersubjective as well as individual understanding about the activity domain is gradually evolving among the actors.

In Figure 7 an example of a complete spatial domain model for the development activity domain is given. This model should be apprehended as a composite sign where the

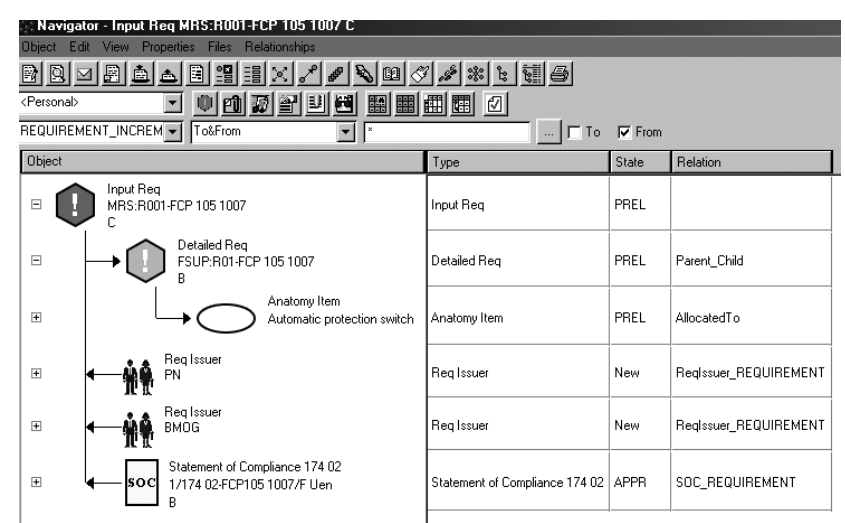

Figure 6. IS implementation - requirement view

signifier aspect of the sign is the material properties of the model, for example, the patterns of lines, icons and text on a piece of paper illustrating the model.

When implemented in the IS, this signifier is complemented with the icons and text visible on the screen. The same icons and texts are used in the IS as in the spatial domain model as can be seen in Figure 6. The reason for this is that the intersubjectivity concerning the signification of the signs becomes more effortless if the signifiers are kept the same in both the model and its implementation. Altogether the fully implemented, detailed model contains several thousand model elements in the IS.

This composite sign is of both the conceptual and symbolic types since the model exhibit both concepts, their relations and text. The sign signifies various phenomena in the coordination activity domain. For example the icons with an exclamation mark in signify 'requirement', a triangle with its tip pointing upwards signifies a 'test object' etc. The signified phenomena are further accentuated by the associated texts in the model.

Furthermore, the complete development activity domain contains several collaborating activity domains with a particular managed item in focus as indicated in Figure 7 (by ovals). This means, for example, that the domain for 'requirement' exhibits a spatial structure such as in Figure 5, a temporal structure (i.e. a process for requirement management), a stabilizing core etc.

\section{Results}

In this section we summarize the results from applying the framework in the Ericsson practice from the early 1990-ies to this date. Throughout this period the author has been active in this effort, first as an actor initiating, promoting and deploying the framework in the Ericsson practice and after 1998 as a researcher as well. The focus of the research has been to identify the effects of the framework on coordination using the activity domain construct as a theoretical guide for data collection and analysis. Thus, from a scientific point of view the research can be characterized as action research [22] concerning a longitudinal single-case, multiple unit of analysis case study 


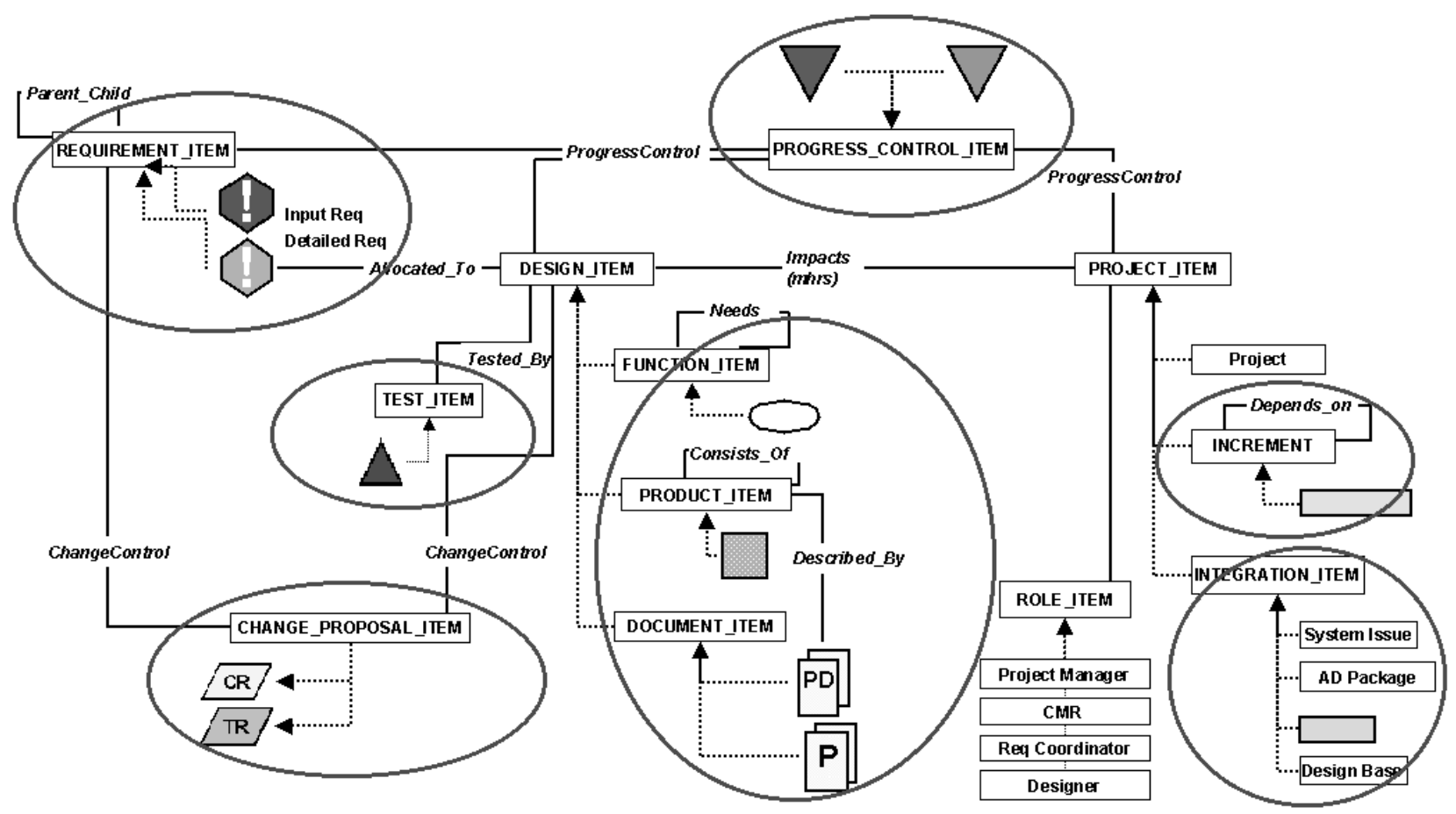

Figure 7. An example of the spatial domain model

[23].

The empiri is collected from notebooks, documentation, data files, e-mails etc. In addition to that 12 interviews with various stakeholders around Ericsson have been made. The interviews were based on a semi-structured questionnaire with open questions and lasted for about $1-2$ hours each. After transcription the interviews were checked with the interviewees for misunderstandings and clarifications.

\subsection{The history of the framework}

Naturally, the framework was not conceptualized in its current form from the beginning. It has been gradually forged in the interaction between the basic praxis perspective of the author, the experiences made and the scientific grounding after 1998. Some major events in this undertaking are:

- 1990: The temporal domain model is employed in process modelling efforts. A particular form of entity based process models [21] is used in contrast to the more common activity based process models in order to focus on entity dependencies rather than activity dependencies.

- 1992: The first elaboration of the domain translation model is done.

- 1996: The spatial domain model is used in elaborating a method package for incremental development of large software development projects. No specific tool is developed for the package, which is used in a development project for the Japanese market.

- 1996: The author encounters with the IS which from that time on is used as the domain articulation tool: the commercial product data management (PDM) system eMatrix. The reason why eMatrix is chosen is the ease by which the models in the framework can be implemented and changed.

- 1997: Based on the experiences from using the method package, the first implementation of the IS is done in order to support the coordination of incremental development according to the package. This implementation is prototyped in two projects, one in Germany and one in Sweden.

- 1998, Q1: The work with the method package and IS is entering a hibernating phase due to a corporate decision to transfer the responsibility of software development methods and tools to a major software vendor outside Ericsson. The author starts his scientific studies. The experiences so far are reported in [25].

- 1998, Q4: The framework is revived. It is decided to try it out in a project developing a new switching equipment. In particular the IS and the spatial domain model is used. This project is distributed to Australia, Italy and Sweden. The focus is on requirements, engineering change orders, baselines and milestones.

- 1999, Q3: Severe performance problems are experienced at the Australian site. These were eventually solved with a new type of web-client. Three more projects start using the framework.

- 2000, Q1: Another IS installation is opened up in Germany. The focus here is on coordinating the integration of increments in the mobile switching centre node in 
the $3:$ d generation mobile systems.

- 2000, Q2: A second IS installation is opened up in Sweden for coordinating projects concerning the base station controller node in the GSM mobile network.

- 2000,Q3: A coordinated development of an Ericsson common IS application is started up.

- 2001, Q2: A corporate agreement signed with Matrix One, the vendor of the IS.

- 2001, Q4: The main 3:rd generation mobile development project starts using the IS and the spatial domain model.

Currently (Q2, 2002) there are about 30 main projects and subprojects using different parts of the framework at Ericsson, mainly for managing requirements, engineering change orders and increment integration coordination.

\subsection{Effects of the framework}

A preliminary analysis of the effects of the framework has been made. The overall results indicate that the Framework contributes positively to the activity of coordinating the development of complex systems. For example, the project manager in the first project using the framework made this statement after the framework had been in use for about two years:

"Well, the positive effects that we have, that is that we have an integrated project support system where we have tremendous possibilities to improve, continuously improve our operations. We have a good support for configuration management, our engineering change requests are in order, our baselines are in order etc. In addition I think that we have the possibilities to manage requirements in a good way and make them obvious and we can achieve a very clear traceability all the way from customer requirements one might say" (Project manager 1).

Another indication of the positive effects is the spread of the usage of the framework between 1998 and today.

Some other observations are:

- Shared understanding: To achieve a shared understanding about the activity domain is a very cumbersome endeavor. This concerns all constituents of the activity domain. Two reason for this can be identified. One is that the models and the IS implementation necessitates an articulation of the traditional, often unreflected way of working. An example of this a lengthy discussion among experienced configuration managers concerning the essence of a 'baseline', a central concept in their practice. This discussion could not be resolved which meant that two different models of the baseline had to be implemented in the IS. The second reason is that the framework makes possible new ways of working which have to acquire intersubjectivity. An example of this is previously mentioned transition to managing requirements as individual objects.

- Conflicts: Several severe conflicts could be identified. One of them occurred in 1998 and had its origin in the previously described decision to outsource the responsi- bility of software development method and tools to a major vendor outside Ericsson. The corporate policy was that the tool suite provided by the vendor should be used. However, the project that wanted to use the IS in the framework did not feel that the vendor tool suite fulfilled their needs. The solution was a decision to go ahead with the IS as a 'gap filler' until the vendor could provide a similar tool in their suite, something which never happened. Another major conflict evolved around the choice of the IS. This system was apprehended as a PDM system in conflict with corporate policies regarding PDM systems. This also means that the framework initiative was never endorsed by topmanagement, which obviously is a major threat to the continued usage of the framework in the organization.

- Performance: The work with the framework was very close to be shut down in 1999 as a results of the previously mentioned IS performance problems experienced in Australia. These problems caused a lot of anger and frustration among the users.

- The importance of alternating between reflection and action: The evolutionary way of working makes possible a fast growth of functionality at a comparable low effort. After one and a half year starting in Nov. 1998 the spatial domain model in Figure 7 had evolved. This model comprises most of the managed item types which have been used ever since. Several hundred alterations were made during this period in the IS implementation due to new insights, new requirements on the coordination scope, growing shared understanding, plain errors in the implementation etc. In this process, the activity domain was gradually structured both spatially and temporally to suit the needs of the project. The total effort during this period was about 6000 man-hours which is very small for this type of global IS implementations. On the other hand, if the alternation between reflection and action is broken, the progress slows down. One example of this was an attempt to maintain a IS independent variant of the spatial domain model. In less than one year this model became a reified object without any practical significance ("a piece of paper on the wall").

- A sense of connectedness: The understanding of dependencies has increased as compared to the traditional way of working where dependencies are specified in documents. For example, one actor expressed this in the following way: "... before every role maintained a piece of information it was responsible for. But in the end all pieces together, they should build an overall picture and what eMatrix enables us to get, this full picture also to cross the border and see "aha this is information somebody else in another role thinks is connected to this one" that is a complete picture of the overall view and not just the limited view the person is responsible for. That is the main benefit I think." (Local Champion 2).

- The role of signs in balancing between tradition and 
transcendence: The introduction of a new way of working in an activity domain means that an existing work practice is changed. This change includes traditional and well as new elements which often can be interpreted in semiotic terms as changing the signifier while keeping the signified aspect of the sign more or less the same. For example, the transition from managing requirements as documents to managing individual requirements in the IS means that the new signifier (an icon in the IS) must acquire a shared significance among the actors that are impacted by requirements in the IS. At the same time however, actors not involved in the new way of working remain with the old signifier (the document type number). These circumstances can be analyzed in terms of a conflict between the significance of signifiers among actors. This conflict was gradually resolved as the intersubjectivity about the new signifier spread among actors.

- One IS supporting the coordination: All information regarding coordination is found in one place for all stakeholders. Previously, the same information element was stored in local storages, mainly Excel spreadsheets. Furthermore, tools which are specialized to support one type of management, for example, requirement management, may now be replaced by one tool comprising all management types. This represents a potential huge cost saving which so far has not been fully realized, mainly due to existing work practices which are hard to change.

- Implementation and deployment: A new working practice requires much more support and active implementation during the initial phases than was estimated. There is also a great need for a prototyping phase before the IS is launched in a production project. Also, the expansion to include more projects must not come too early.

- Balancing between central control and local autonomy: The different process maturity at local development sites in Ericsson means that in practice, it is impossible to impose the same way of working at all sites. There must be a balance between central control and local autonomy. For example, at the three different IS sites separate models and implementations have evolved. Although the coordination works well for these sites, a major concern is how to exchange information between the sites. The strategy for achieving this is to identify those items in the models and the implementations which are mandatory to coordinate over the entire Ericsson and leave the rest to each site to decide on.

\section{Discussion}

In this section we will briefly discuss the influences from the theoretical praxis perspective in the study. We will do this using the fundamental constituents as a theoretical guide.

The notion of activity domains provides a way to conceptualize the mutual dependencies between the fundamental constituents. Usually in organizational reengineering efforts only one of the constituents are in focus at a time. For exam- ple, in Business Process Reengineering (BPR) programs constituent temporality is emphasized [26]. Another example are the huge efforts of deploying Enterprise Resource Planning (ERP) systems where the tool constituent is in focus [27]. However, the experience from the study indicate that these constituents cannot be treated as independent. A change in anyone of the tool, temporal, and spatial constituents affects the others as well.

The theoretical perspective emphasizes intersubjectivity or shared understanding. There is an abundance of empirical evidence in the study for the importance of this constituent. The cost of achieving shared understanding is seldom recognized, yet it may well be one of the major costs in articulating the activity domain. Since the framework includes a semiotic perspective and articulation strategy based on experiential learning, we claim that the framework is an efficient way of achieving shared understanding about coordination. The fast evolution in the first project is an indicator of this. However, more research is needed to properly ground this claim.

The constituent contextuality is given a concrete form in the spatial domain model as the example in Figure 7 shows. The spatial model has been the most frequently used model in the reflection phase.

The temporal model is not nearly as salient as the spatial model. The only indication of this model is the state chains associated with the types in the spatial model.

The domain translation model has not been articulated at all. It has been mainly used as a place-holder for discussion concerning the borderlines between different activity domains.

There are well grounded empirical indications that the evolutionary IS development approach is superior to other approaches at Ericsson concerning implementation time, cost, functionality and flexibility. We consider this to be one of the major results of the theoretical praxis perspective (see [12] for details).

The major importance of the stabilizing core constituent has been to initiate a discussion about the importance of the central control - local autonomy dimension. The traditional understanding in the organization is that a centralized information architecture, process model IS implementation is possible for all activity domains across all Ericsson. We argue against that, simply because the cost of achieving a shared understanding will be staggering.

\section{Conclusions}

We have described a theoretical approach based on praxis which is suitable to inform the articulation of coordination activities structured as activity domains. Furthermore, we have reported on some results from applying a framework, based on this approach, in the Ericsson development practice. The results show that the theoretical approach is capable of informing practical support for the coordination of the development of complex systems. 


\section{References}

[1] Hegel, G. W. F. (1977) Phenomenology of spirit, transl. by A.V. Miller; with analysis of the text... by J.N. Findlay, Oxford: U.P. 1977

[2] Berger, P. and Luckmann, T. (1966): The Social Construction of Reality, London 1991: Reprint by Penguin Books.

[3] Kosík, K. (1976), Dialectics of the concrete, Reidel, Dordrecht.

[4] Giddens, A. (1984) The Constitution of Society, Cambridge: Polity Press

[5] Seo, M. and Creed, W. (2002) Institutional Contradictions, Praxis and Institutional Change; a Dialectical Perspective, Academy of Management Review, vol 27, no. 2, pp. 222-247.

[6] Jones, M. (1999) Structuration Theory, in Rethinking management information systems: an interdisciplinary perspective, Currie W, Galliers R (Ed), Oxford: Oxford Univ. Press, 1999

[7] Iivari, J. and Lyytinen, K. (1998) Research on Information Systems Development in Scandinavia - Unity in Plurality, Scandinavian Journal of Information Systems, 1998, 10 (1\&2):135186

[8] Latour, B. (1998) Teknik är samhället som gjorts hållbart, i Latour, B. (1998) Artefaktens återkomst. Ett möte mellan organisationsteori och tingens sociologi, Nerenius \& Santérus Förlag, Stockholm (in Swedish)

[9] Latour, B., (1986). The powers of association. In Law, J. (ed.). Power, action and belief. A new sociology of knowledge? London: Routledge, pp. 264-280.

[10]Engeström, Y. (1999) Activity theory and individual and social transformation, in Engeström Y, Miettinen R, Punamäki RL (eds. 1999) Perspectives on Activity Theory, Cambridge UK: Cambridge University Press.

[11] Stamper, R. K. (2001) Organisational semiotics. Informatics without the computer, in Liu K, Clare RJ, Andersen PB, Stamper RK (eds. 2001). Information, organisation and technology. Studies in organisational semiotics, Boston: Kluwer Academic Press, pp. $115-171$

[12] Taxén, L. (2002) A Framework for Coordinating the Development of Complex Systems, Dissertation, Linköping: Linköping University (in progress).

[13]Malone, T. and Crowstone, K. (1994) The Interdisciplinary Study of Coordination, ACM Computing Services, Vol 26, no 1, pp. 87-119.

[14]Innis, R. (1985) Semiotics. An Introductionary Anthology (edited by Innis R), Bloomington, USA: Indiana University
Press.

[15] Vološinov, V.N. (1986/1929) Marxism and the Language of Philosophy, London: Harvard University Press. Appeared first in V.N. Vološinov, Marksizm i filosofija jazyka: osnovnye problemy sociologiceskogo metoda $v$ nauke o jazyke, Leningrad 1929.

[16]Gärdenfors, P. (2000)Conceptual Spaces: The geometry of thought, Cambridge, Massachusetts: MIT Press.

[17]Chalmers, A. F. (1976) What is this thing called science?, University of Queensland Press, St Lucia, Queensland.

[18]Israel, J. (1979) The language of dialectics and the dialectics of language, New York: Humanities P.

[19]Kolb, D. A. (1984) Experiential Learning: Experience as the Source of Learning and Development, Prentice Hall,Englewood Cliffs, New Jersey

[20]Humphrey, W. and Kellner, M. (1989), Software Process Modelling: Principles of Entity Process Models, CMU/SEI-89-TR2, Software Engineering Institute, Carnegie Mellon University

[21]Kristensen, J. (2001) Evolutionary Information System Development, Proceedings of the 24th Information Systems Research Seminar in Scandinavia (IRIS 24), Ulvik, Norway.

[22]Checkland, P. (1991) From Framework through Experience to Learning: the essential nature of Action Research, in Information Systems Research, Contemporary Approaches and Emergent Traditions, Nissen, H.E. \& Hirschhem (Editors), pp. 397 403.

[23]Yin, R. K. (1989) Case study research. Design and methods, London: Sage

[24]Gandhi, M. and Robertson, E. (1992) A Specification-based Data Model, Indiana University Computer Science Department Technical Report TR344, Indiana University, Indiana. http:// www.cs.indiana.edu/ftp/techreports/index.html (May 2002)

[25]Taxén, L. and Karlsson, E. A. (1998), Incremental Development for AXE 10, Ericsson Conference on Software Engineering, Frankfurt.

[26]Hammer, M. (1990) Reengineering Work: Don't Automate, Obliterate, Harvard Business Review, pp. 104-112.

[27]Akkermans, H. and van Helden, K. (2002) Vicious and virtuous cycles in ERP implementation: a case study of interrelations between critical success factors, European Journal of Information Systems (2002) II, pp. 35-46 